\title{
Angiogenesis
}

\section{Angiogenic Therapy Using Fibroblast Growth Factors and Vascular Endothelial Growth Factors for Ischemic Vascular Lesions}

\author{
Chiharu Iвukryama, MD
}

\section{Summary}

Angiogenic therapy using fibroblast growth factor (FGF) and vascular endothelial growth factor (VEGF) is being developed as a novel therapeutic strategy to obtain restoration of blood fiow around the ischemia in cases of ischemic cardiovascular disease. In addition, arterial gene therapy through gene transfer by VEGF genes has now reached the stage of clinical application.

Through in vivo animal experiments to determine the angiogenic effects of FGF and VEGF, we hope to obtain clues concerning the clinical applications of these methods.

Methods-1: Twenty-three adult dogs were divided into 3 groups as follows: Group A-1: $\quad 20 \mu \mathrm{g}$ of bFGF was administered intravenously simultaneously with heparin three times per week in 4 dogs.

Group A-2: $20 \mu \mathrm{g}$ of bFGF was administered intravenously three times a week without heparin in 4 dogs.

Group B: $\quad 20 \mu \mathrm{g}$ of bFGF was administered intramuscularly three times per week in 5 dogs.

Group $C$ : Sham operation control group consisting of 10 dogs.

Local ischemia was created in the hind limbs of animals in groups A-1, A-2 and B through ligation of the femoral artery. Selective femoral arteriography was performed immediately after ligation at 1 week and 2 weeks postoperatively. Biopsy was also performed either at 1 week or 2 weeks after ligation.

Results-1:

(1) The percent increase in number of collateral vessels of the ischemic zone, as recognized on arteriography, was greater in the bFGF groups compared to group $\mathrm{C}$.

(2) The increase in collateral vessels peaked at 1 week.

(3) No difference in angiogenic effect was observed in relation to the method of administration.

(4) The combined administration of heparin had no angiogenic effect.

(5) The hemoglobin content of the biopsy specimens was significantly greater in the 3 groups receiving bFGF compared to group $\mathrm{C}$.

Methods-2: The same study was performed using VEGF as detailed in Method-1.

From the Second Department of Internal Medicine, Tokyo Medical College, Tokyo, Japan.

Address for correspondence: Chiharu Ibukiyama, MD, Second Department of Internal Medicine, Tokyo

Medical College, Nishi-shinjuku 6-7-1, Shinjuku-ku, Tokyo 160, Japan.

Received for publication November $20,1995$.

Accepted November 27, 1995. 
Results-2: As in the first experiment, a significant increase in collateral vessels was seen in the VEGF group compared to the control group.

Both exogenous bFGF and VEGF significantly promote collateral vessel development and appear to be effective novel therapeutic agents for the treatment of ischemic disease. (Jpn Heart J 1996; 37: 285-300)

Key words: Acidic fibroblast growth factor Basic fibroblast growth factor Vascular endothelial growth factor Collateral vessels Heparin Gene transfer Angiogenic therapy Gene therapy

1 ECENT progress in molecular biology has made the synthesis of various cytokines possible. In addition, the development of recombinant genetic techniques has opened a completely new avenue in terms of therapeutic strategy, namely gene therapy.

With increases in the frequency of ischemic diseases due to arterial sclerosis, various approaches, including percutaneous transluminal angioplasty (PTA), percutaneous transluminal coronary angioplasty (PTCA), bypass graft surgery and coronary artery bypass graft $(\mathrm{CABG})$ have been developed to treat chronic obstructive diseases of the arteries of the limbs such as arteriosclerosis obliterans (ASO) and angina pectoris and myocardial infarction related to coronary artery sclerosis.

In the United States approximately 150,000 people undergo amputations of the lower limbs annually due to ASO, ${ }^{1 /}$ and in such cases the prognosis is usually extremely poor. ${ }^{2)}$

While PTCA and CABG can be extremely effective in cases of ischemic heart disease (IHD), they are sometimes contraindicated for a variety of reasons. This means that a more multidisciplinary approach is necessary for the treatment of ischemic diseases. To that end, the author is studying the effectiveness of photodynamic therapy in preclinical studies using a photosensitizing substance and laser photoradiation to obtain regression of atherosclerosis.

Angiogenesis involves the sprouting of endothelial cells from preexisting microvessels and subsequent growth into new vessels. Apart from the physiological angiogenesis that is seen with the normal growth and development of the body, there are conditions involving angiogenesis, or neovascularization, such as diabetic retinopathy, malignant neoplasm, rheumatoid arthritis, psoriasis, angioma, and angiofibroma, among other conditions.

Fibroblast growth factor (FGF) and vascular endothelial growth factor (VEGF), both of which are peptide cell growth factors, have angiogenic effects and promote the development of revascularization in ischemic disease.

Angiogenic therapy using these growth factors holds much hope for the treatment of ischemic diseases. 
This paper presents the results of the author's study of angiogenic therapy using recombinant FGF and VEGF in an animal model of acute arterial occlusion, against the background of data reported in the international literature. The present status of gene therapy using VEGF for ASO is also discussed.

\section{FGF}

FGF is a cell growth factor which is purified from the brain and pituitary gland and which was first localized in 1974 by Gospodarowicz. ${ }^{3)}$ FGF is actually a family of 9 substances consisting of acidic FGF (aFGF), basic FGF (bFGF), INT-2 (FGF-3), HST-1 (k-FGF, FGF-4), FGF-5, HST-2 (FGF-6), KGF (FGF-7), and FGF-8/AIGF and FGF-9. aFGF has a molecular weight of $16 \mathrm{kDa}$, is a cationic polypeptide made up of 140 amino acids, and possesses $55 \%$ sequence homology with bFGF.

bFGF has a molecular weight of $18 \mathrm{kDa}$ and is made up of 154 amino acids. Research into the subcellular distribution of bFGF has indicated that 18 $\mathrm{kDa}$ bFGF is located mainly in the cytosome, but there is also high molecular weight (22 kDa, $24 \mathrm{kDa}$ ) bFGF distributed in ribosomes and nuclei. ${ }^{4)}$ Both aFGF and $\mathrm{bFGF}$ are non-secreted growth factors lacking a signal peptide sequence. Moreover, both of them have a strong affinity for glycosaminoglycan heparin. ${ }^{5)}$

aFGF is recognized in the brain, retina, kidney, smooth muscle cells, etc., while bFGF is seen in the brain, pituitary gland, retina, myocardium, liver, kidney, adrenal cortex, bone, placenta, macrophages, endothelial cells and smooth muscle cells.

FGF is involved in autocrine or paracrine modulation of cell growth and transformation in various physiological and pathological situations. ${ }^{6,7)}$ The physiological activity of FGF includes acting as a potent mitogen stimulating angiogenesis, brain development, cartilage formation, soft tissue repair, etc., and also the proliferation, migration and differentiation of cells of mesenchymal or neuroectodermal origin. Concerning its involvement with pathological processes, it is rclated to the proliferation of capillaries which can be related to the pathophysiology of disease, i.e. the process of angiogenic disease.

\section{FGF angiogenesis}

Previously, the formation of collateral vessels was thought to derive purely from physical phenomena such as anastomoses of precxisting vessels causing changes in arterial blood pressure and blood volume, resulting in dilation and development of the collateral vessels.

However, the development of collateral vessels in dogs following gradual occlusion of the left circumflex coronary artery was accompanied by proliferation of endothelial cells and vascular smooth muscle cells in vessels showing anasto- 
mosis formation, and there was an increase in ${ }^{3} \mathrm{H}$-thymidine uptake. It was also seen that there was an increase in ${ }^{3} \mathrm{H}$-thymidine uptake in adjacent venules and capillaries which did not have pressure overload. ${ }^{8)}$ Therefore at present it is not possible to explain collateral vessel formation on the basis of pressure overload and volume overload alone and it is very likely that cell proliferation factors are involved.

The collateral vessels that develop from the peripheral arteries of the extremities and coronary arteries consist of not only vessels with capillary-like diameters but also consist of arterioles and larger vessels which include smooth muscle in their composition. It is also difficult to explain the development of collateral vessels in vivo based only on the angiogenic process seen in vitro.

Considering the results of Pasyk et $\mathrm{al}^{8 /}$ with regard to the time of appearance of the ${ }^{3} \mathrm{H}$-thymidine uptake peak and collateral vessels, it appears likely that the initial increase in collateral flow is related to the opening of preexisting channels, and subsequent increase of collateral flow is probably related to new vessel growth.

FGF was first reported to be a growth factor with regard to fibroblasts and was later reported to have a promoting effect on the proliferation of cultured vascular endothelial cells and smooth muscle cells. ${ }^{\text {9) }}$ The mechanism of FGF at the cultured cell level has been shown to include phenomena such as proliferation of vascular endothelial cells as well as microvessel-like structure formation of endothelial cells and induction of secretion of proteolytic enzymes by extracellular matrix in three-dimensional collagen gels. ${ }^{10}$

In vitro angiogenesis by $\mathrm{FGF}$ is thought to include the following processes:

(i) destruction of basement membrane

(ii) migration of endothelial cells into extracellular matrix

(iii) proliferation of endothelial cells

(iv) tubule-like structure formation

(v) reconstruction of basement membrane and migration of pericytes.

As described above, angiogenesis caused by growth factors is basically at the capillary-like structure level. The development of collateral vessels probably involves the interrelationship of the adenosine accompanying ischemia and other metabolites, the development of anastomoses through channel opening of preexisting vessels, and the above angiogenic process.

aFGF also has the effect of promoting the platelet-derived growth factor (PDGF) A-chain gene expression of endothelial cells. ${ }^{11}$ Since PDGF is a promoting factor causing strong proliferation of smooth muscle cells, FGF may have its angiogenic effect via PDGF. 


\section{Mechanism of the effects of FGF}

Since FGF lacks the signal peptide sequence that would enable it to be secreted extracellularly, most of it remains sequestered within the cell that produced it and it does not show the secretory characteristics of peptide hormones. ${ }^{12,13)}$ Extracellular release of FGF is caused by cell damage or cell death due to acidosis and/or accumulation of metabolites associated with ischemia. ${ }^{14}$ )

Since FGF has a strong affinity for heparin, it is also referred to as heparinbinding growth factor (HBGF) and it is known that in the extracellular environment it has affinity for heparin-like substances (mainly heparan sulfate). Heparin is a potent modulator of the physiological activation of aFGF, bFGF (HBGF-1, HBGF-2). It increases the affinity of the aFGF receptor and also increases the potency of mitogenic activity through stabilization of the FGF molecule. ${ }^{15}$ )

The importance of heparin with regard to $\mathrm{bFGF}$ is the protection given by the former to the latter against denaturation or enzymatic degradation due to exposure to acid or heat. However, there is also a report on an experiment in which the potency of bFGF was reduced through cultivation of bFGF in medium that contained heparin. ${ }^{16}$

When FGF is released extracellularly, it binds with heparan sulfate of the basement membrane of cells, where it is stored. In other words, for bFGF to bind to the receptor on the cell membrane, it is necessary for cell membrane heparan sulfate to be present. bFGF can bind with receptors through binding of the $\mathrm{bFGF}$ heparin-binding domain and cell membrane heparan sulfate. ${ }^{17)}$ With damage to the cell, enzymatic degradation through proteolytic enzymes such as heparinase, plasmin, phospholipase $\mathrm{C}$ and catepsin $\mathrm{D}$, allows binding dissociation to take place and the effects of bFGF become apparent.

There are abundant amounts of type IV collagen and laminin in the cellular basement membrane and also abundant type I and III collagen and fibronectin in connective tissue. In order for the previously described angiogenic process to proceed, it is necessary for plasminogen activator, collagenase or stromelysin to be sccretcd. ${ }^{18)}$

While procollagenase and prostromelysin are secreted by endothelial cells, in order for these to express their activity it is necessary for them to be converted by plasmin into their active type. ${ }^{19)}$ Plasmin is converted from plasminogen by plasminogen activator (PA), which is produced by endothelial cells. The endothelial cells of the capillaries also produce plasminogen activator inhibitor (PAI-1) and the tissue inhibitor of metalloproteinase (TIMP) which inhibits collagenase and stromelysin. ${ }^{20)}$

Since bFGF acts to promote secretion of not only PA from endothelial cells and PAI-, it appears to regulate the balance of angiogenic and anti-angiogenic effects. In other words, it regulates the mechanism of the destruction of basement 
membrane and migration of endothelial cells into the extracellular matrix.

\section{Experimental angiogenesis using bFGF}

There have been many animal experiments using angiogenic growth factor to develop collateral vessels in order to obtain improvement of severe ischemia of muscles of the lower or hind limbs or myocardium caused by arterial occlusion. FGF was first used for that purpose.

Method: The animal study protocol was approved by the Ethics Committee of Tokyo Medical College.

Surgical procedure: A total of 23 adult mongrel dogs of either sex, weighing 8 to 11 $\mathrm{kg}$, were anesthetized with $0.5 \mathrm{mg} / \mathrm{kg}$ pentobarbital sodium intravenously. Selective left femoral arteriography was performed after the left femoral artery was isolated immediately below the inguinal ligament and was occluded by ligation. Treatment: Twenty-three dogs were divided into three groups. Group A consisted of 8 dogs which received an i.v. bolus injection of $20 \mu \mathrm{g}$ of bFGF 3 times a weck for 2 wceks. Group B consisted of 5 dogs which reccived 3 weckly injections of $20 \mu \mathrm{g}$ bFGF for 2 weeks intramuscularly near the ligated area. Group $\mathrm{C}$ consisted of 10 dogs which received a sham operation.

Group A was further subdivided into a group of 4 dogs which received an injection of 2,000 units of heparin at the same time as bFGF and another group of 4 dogs that did not receive a heparin injection, in order to determine the influence of heparin on the angiogenic effects of bFGF.

Selective femoral arteriography was performed immediately, 1 week, and 2 weeks after the surgical procedure. In addition, muscle biopsy of the occluded area was performed 1 and 2 weeks after the procedure. The bFGF (KCB-1) was generously supplied by Kaken Pharmaceutical Co. Japan (Tokyo, Japan).

Measurement: The angiography films obtained on each occasion were magnified and the amount of increase in small vessels within an area $5.0 \times 5.0 \mathrm{~cm}^{2}$ centered on the site of occlusion was measured and compared. Biopsy specimens were used for histological investigations with $\mathrm{HE}, \mathrm{EVG}$ and immunostaining.

Endothelial cells showing a positive reaction on immunostaining were compared in the 3 groups in a neovascularization study. Furthermore, each group was compared in terms of hemoglobin content per mg of biopsy specimen material. In addition, the additive effects of combined heparin and bFGF administration were also studied.

Results: Figure 1 shows the results of selective femoral arteriography immediately and 1 week after ligation of the femoral artery in groups $A$ and $C$. The development of collateral vessels was markedly greater in group $A$ than in group C. The neovascularization network within a radius of $100 \mu \mathrm{m}$ was extremely marked in group A. Comparing the number of vessels that could be counted on 




Figure 1. Selective femoral arteriograms of two dogs in group A and group C. A and $B$ are arteriograms obtained immediately after the surgical procedure in group $C$ and group A dogs, respectively. $\mathrm{C}$ and $\mathrm{D}$ are arteriograms recorded one week after the procedure in group $\mathrm{C}$ and group $\mathrm{A}$, respectively.

magnified selective femoral arteriography 1 week after the surgical procedure revealed increases in groups $\mathrm{A}$ and $\mathrm{C}$. The percent increase in number of newly developed vesscls was $55 \%$ in group $\mathrm{A}$, while it was less than $20 \%$ in group $\mathrm{C}$ (Figure 2-A). However, between 1 and 2 weeks after the surgical procedure, there was no significant increase in the number of vessels in the two groups, each of which showed a further increase of less than 20\% (Figure 2-B). The angiogenic effect of exogenous recombinant bFGF reached a peak at approximately 1 week after administration.

In the biopsy specimens, the unit area of vessels showing a positive immunostaining response was significantly greater in the bFGF groups than in 


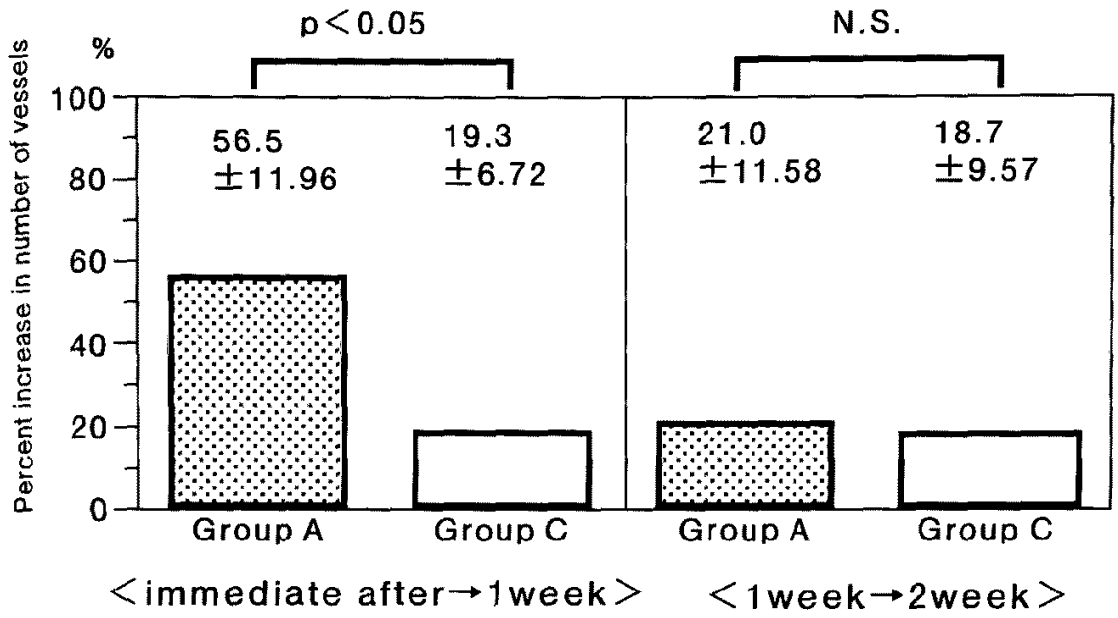

(A)

(B)

Figure 2. The percent increase in number of collateral vessels in arteriograms in group A and group C. The percent increase in number of vessels during the first week is shown in (A) and during the second week in $(B)$.

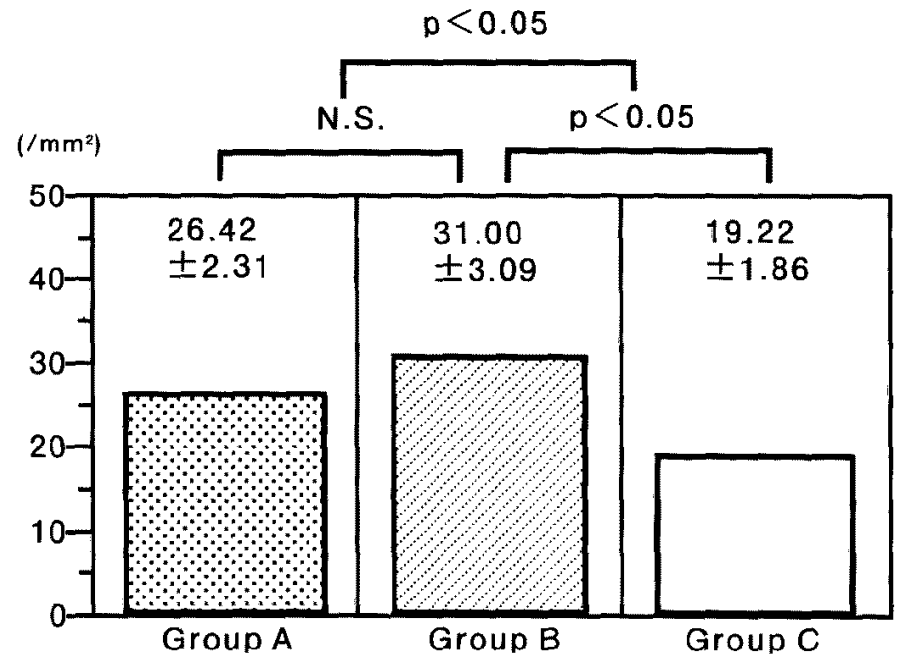

Figure 3. The number of capillaries showing a positive response to immunostaining in the three experimental groups.

group $\mathrm{C}$, but there was no significant difference between the two bFGF groups (Figure 3). There was no difference in the angiogenic effect in relation to the method of administration of exogenous bFGF. A significantly greater amount of hemoglobin content per mg of biopsy specimen was seen in group B compared to group C (Figure 4). The increase in the number of vessels at 1 week after the surgical procedure in the group Al subgroup receiving heparin simultaneously with bFGF was not significantly different from that of subgroup A2 which re- 


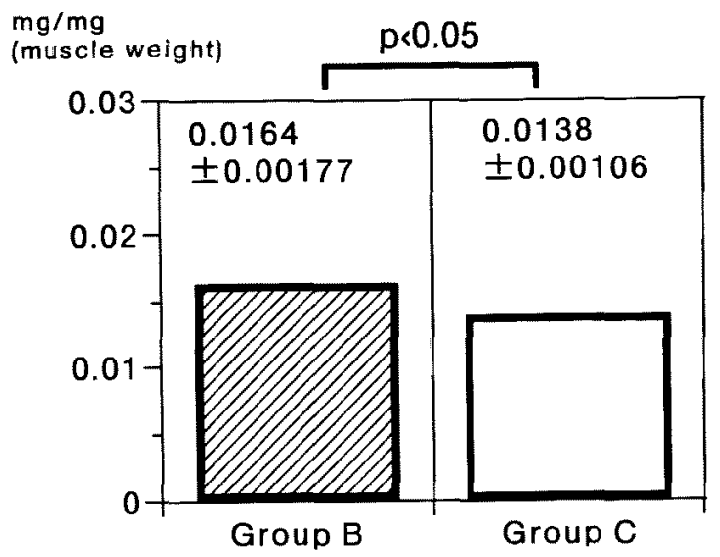

Figure 4. Hemoglobin content in muscle biopsy specimens in group B and group C.

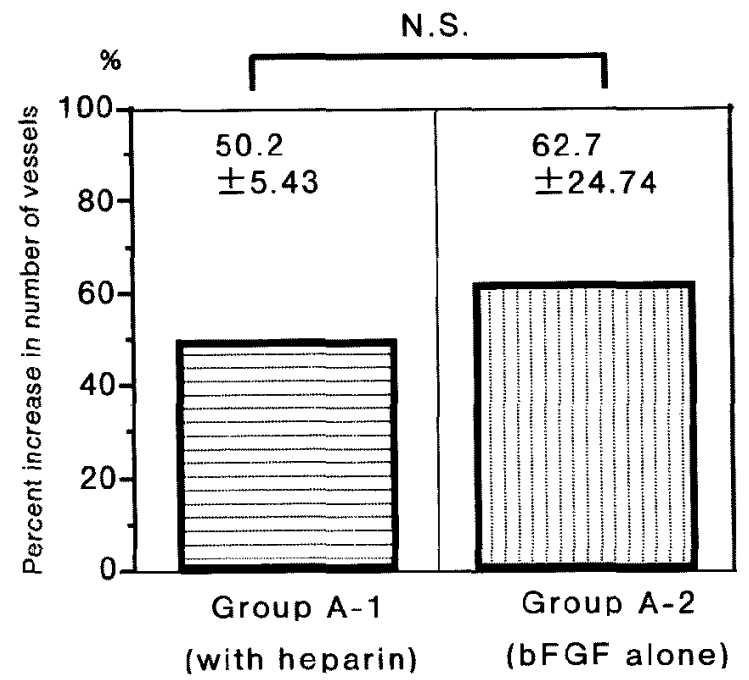

Figure 5. Effect of heparin on the \% increase in number of vessels 7 days after surgical procedure.

ceived bFGF alone (Figure 5).

As noted previously, when heparin is added to the medium of aFGF in vitro, the potency of aFGF is increased, whereas a decrease in that of bFGF has been reported. ${ }^{16)}$ The in vivo effect of combined administration of heparin and exogenous bFGF requires further study.

Yanagisawa-Miwa et $\mathrm{al}^{21)}$ studied the angiogenic effect of exogenous bFGF by occluding the left anterior descending artery in dogs, causing experimental myocardial infarction, and then infusing $10 \mu \mathrm{g}$ of bFGF into the left circumflex artery at 30 minutes and 6 hours after the occlusion. In the group with bFGF administration, LVEF was significantly greater than in the control group, and at 
1 week, the infarct size was also significantly less than that of the control group. On coronary angiogram many thin vessels about $100 \mu \mathrm{m}$ in diameter were seen extending towards the infarct zone from the site of bFGF infusion in the left circumflex artery. These findings were similar to those obtained in our study of the femoral artery in dogs.

In the histopathological investigation of Yanagisawa-Miwa ${ }^{21)}$ there was a significant increase in the arterioles and capillaries around the periinfarct zone on the left circumflex artery at which bFGF had been induced. These findings suggest that angiogenesis due to bFGF in acute myocardial infarction is related to reduction in the size of the infarct zone and improvement of LVEF.

Unger et al, using gradually increased stenosis of the canine left circumflex artery by employing an ameroid constrictor, examined the effect of bFGF on collateral blood flow in the ischemic myocardium. ${ }^{22)}$ In this experiment $110 \mu \mathrm{g}$ bFGF was delivered by direct bolus injection for 28 consecutive days in the collateral-dependent zone, beginning 10 days after the application of the ameroid constrictor.

The blood flow ratio in the collateral-dependent zone compared to the normal zone was significantly greater in the bFGF group compared to the control group. In addition, the numerical density of distribution vessels and the amount of endothelial cell DNA synthesis in the collateral dependent zone was significantly greater than in the control zone.

Landau et al infused bFGF into the intrapericardial space of a rabbit model with chronic myocardial ischemia and reported the promotion of epicardial small vessel growth which was amplified by the presence of left ventricular hypertrophy. ${ }^{23)}$

Chleboum et al reported increased recovery of blood flow after administration of heparin together with polymer discs containing bFGF in rats in which severe hind limb ischemia had been induced. ${ }^{24)}$

Baffour et al created an acute ischemic model of the hind limbs of rabbits and administered either $1 \mu \mathrm{g}$ or $3 \mu \mathrm{g}$ of bFGF daily by intramuscular injection. ${ }^{25)}$ Angiography and measurement of capillary density on necropsy specimens showed enhanced growth of collatcrals and angiogenesis in the hind limb with severe ischemia. ${ }^{25}$ )

In a study of the dose-response aspect of the angiogenesis of bFGF, Norrby used a rat mesenteric-window assay system using 3 doses $(10 \mu \mathrm{g}, 100 \mu \mathrm{g}$, and $1,000 \mu \mathrm{g})$ administered intraperitoneally twice daily for 4 and 5 days, and found a direct angiogenic effect of bFGF in the middle dose group $(100 \mu \mathrm{g})$ at day 7 and a peak on day 14 in the $1,000 \mu \mathrm{g}$ high-dose group. ${ }^{26)}$

The fact that in the $10 \mu \mathrm{g}$ low-dose group a peak had not been reached by day 21 or day 28 suggests that the molecular and cellular mechanisms of bFGF- 
mediated angiogenesis are dose-dependent. However, it has also been reported that ischemia caused by high dose exogenous bFGF can cause infarction throughout an extensive area. ${ }^{25)}$

It has also been shown that bFGF strongly immunostains myocardial cells of hypertrophied ventricular septum in cases of hypertrophic cardiomyopathy and hypertrophied myocardial cells after myocardial infarction, and also that it is expressed strongly in the cytoplasm of hypertrophied hearts of pressure overloaded rats and SHR. ${ }^{27)}$ In other words, these findings suggest that there is a possibility that bFGF induces myocardial cell growth and hypertrophy.

While the angiogenic effect expression peak of bFGF appears to be dosedependent, in the clinical application of exogenous bFGF it is important to achieve effects with minimal doses. The experiments of the author and also Norrby ${ }^{26)}$ indicated that the peak of neovascularization was seen within 1 week of administration, based on the results of angiography, and that there was no significant increase thereafter, suggesting that exogenous administration of bFGF should be limited to weekly dosages. However, the mechanism whereby the peak of the angiogenic effect is reached at 1 week is not clear.

It is also necessary to determine whether the new development of vessels appearing after the administration of bFGF continued for a long time after the cessation of bFGF administration.

It is also necessary to determine the effect of combined administration of heparin on the angiogenic effects of bFGF.

\section{VEGF}

\section{Characterization and angiogenic effect}

VEGF is a $45 \mathrm{kDa}$ heparin-binding dimeric glycoprotein and is a vascular endothelial cell-spccific mitogen. Bccausc of its apparent target cell selectivity, it is referred to as vascular endothelial growth factor (VEGF) ${ }^{28)}$ Unlike FGF, VEGF is a typical signal sequence in the $\mathrm{N}$-terminal and is secreted by intact cells, ${ }^{29,30}$ and it is also different from FGF because of its above mentioned endothelial cellspecific character.

Four different subtypes of VEGF have been recognized, each with different numbers of amino acids due to variation in splicing. These monomers are named according to their number of amino acids as $\mathrm{VEGF}_{121}, \mathrm{VEGF}_{165}, \mathrm{VEGF}_{189}$ and $\left.\mathrm{VEGF}_{206 .}{ }^{31}\right)$ The cDNA of each of these VEGF monomers is expressed in human fetal kidney CEN4 cells, and analysis has shown that while $V_{E G F} F_{121}$ and $\mathrm{VEGF}_{165}$ are diffusable, $\mathrm{VEGF}_{189}$ and $\mathrm{VEGF}_{206}$ are non-diffusable, and that the latter bind with cell surface or basement membrane after secretion. ${ }^{32)}$ Furthermore, the VEGF mRNA level increases in cultured fibroblasts and cardio- 


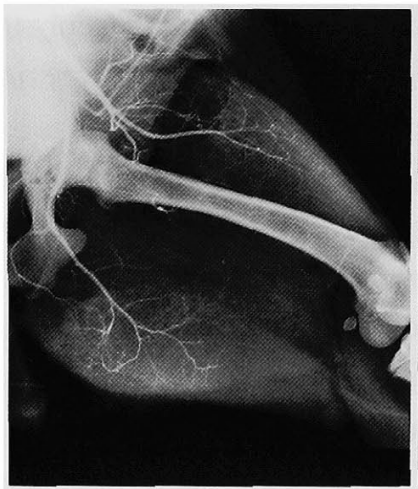

$\mathbf{A}$

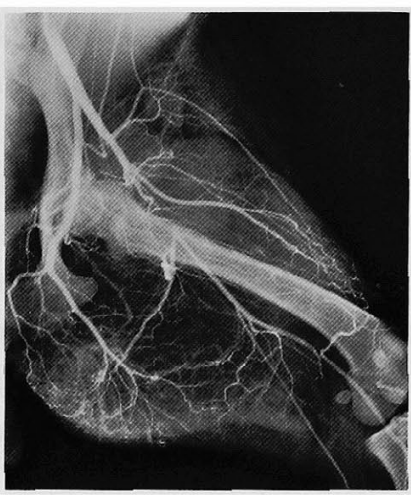

B

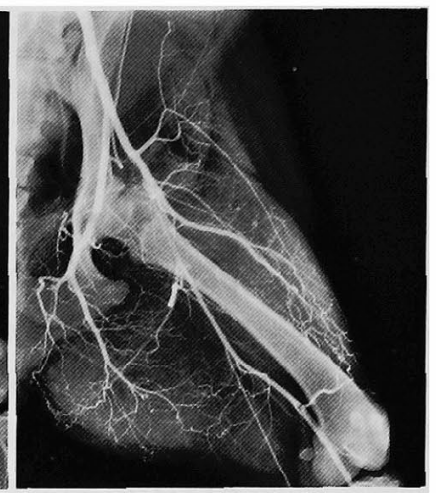

C

Figure 6. A series of selective femoral angiograms in a dog after administration of VEGF. A: immediately after the surgical procedure; B: one week after; and C: two weeks after.

myocytes exposed to hypoxia, therefore, hypoxia is a potent stimulus for VEGF gene expression. ${ }^{33,34)}$

In an experiment involving a single intraarterial bolus injection of 500 to $1,000 \mu \mathrm{g}$ of exogenous VEGF in a rabbit severe ischemic hind limb model, Takeshita et $\mathrm{a}^{35)}$ showed significant augmentation of revascularization in the ischemic region.

Asahara et $\mathrm{al}^{36)}$ showed that local delivery of exogenous VEGF promoted the reendothelialization of rat carotid artery after balloon injury and that it indirectly attenuated smooth muscle cell proliferation. In an experiment using a rabbit hind limb ischemia model, VEGF was shown to enable recovery of endothelium-dependent flow. ${ }^{37)}$ An experiment gradually increasing the degree of stenosis of the left circumflex artery of dogs, using an ameroid constrictor, with injection of $45 \mu \mathrm{g}$ VEGF for 28 days into the coronary artery peripheral to the occluded ischemic myocardium resulted in the development of small vessels perfusing the ischemic myocardium and an increase of $40 \%$ in collateral flow. ${ }^{38)}$

In an experiment similar to that described above with bFGF the author administered VEGF (Pepro Tech Inc., USA) 3 times a week at a dosage of $20 \mu \mathrm{g}$ for one week. A significant increase in revascularization was recognized by angiography of the ischemic hind limb region (Figure 6). The rate of generation of new vessels after the surgical procedure was $46.5 \%$ after 1 week and a further $39.5 \%$ at 2 weeks after the surgical procedure, indicating VEGF has an excellent angiogenic effect.

Unlike FGF and other heparin-binding angiogenic factors, VEGF is a specific mitogen for endothelial cells and also has the advantage of being able to be secreted by intact cells. Therefore VEGF can be considered to be possibly superior to FGF as a therapeutic angiogenic factor. Gene transfer is also being widely 
examined to determine its applications for angiogenesis

In a study by Nabel et al ${ }^{39)}$ involving gene transfer of aFGF to porcine artery, intimal thickening and neocapillary formation was recognized in expanded intima and improved blood flow to ischemic tissue was recognized, suggesting the possible application of gene transfer techniques to genetic intervention. Mesri et al $^{40)}$ suggested the possibility of induction of an angiogenic response in vivo by VEGF gene transfer and other approaches by gene therapy for the treatment of tissue ischemia.

\section{Clinical applications of VEGF gene therapy}

In gene transfer, the most important issue is how effectively and how selectively gene materials can be delivered to the target cells in the vessel wall.

Many studies of gene transfer to target cells have been performed, including studies developing vector systems, studies determining the target sites in vessels and also the development of catheters for the release of gene materials. Vectors used for gene transfer to vascular walls include retrovirus vector, adenovirus vector, plasmid DNA vector, plasmid DNA + liposome vector, and plasmid DNA + liposome + virus envelopes.

Three types of catheters for delivery of gene materials to target sites have becn developed: a double balloon catheter; a porous balloon infusion catheter; and a hydrogel-coated balloon catheter. Ohno et al ${ }^{41)}$ introduced an adenoviral vector encoding the herpes virus thymidine kinase ( $\mathrm{HSV}$-tk) into porcine arteries after balloon injury and reported that intimal hyperplasia decreased after a course of gancyclovir treatment. Gutzman et $\mathrm{al}^{42)}$ reported highly effective and selective effects of adenovirus vector with regard to vascular neointimal cells. In a study using a perforated balloon catheter (Wolinsky), Flugelman et $\mathrm{al}^{43}$ described a procedure completed within 1 minute but reported that there are very few cells showing transduction of genes, indicating the limitations of this method for therapeutic use. This catheter has been recently improved.

In addition, Rome et $\mathrm{al}^{44)}$ reported that there is a limit to the size of particles of gene transfer vectors that could penetrate arterial walls with normal elasticity and that in vivo, correct prediction of distribution of inert tracer particles could indicate the distribution of adenovirus vector. They suggested that this held important implications for the use of adenovirus vectors.

Steg et $\mathrm{al}^{45)}$ reported that, using either a double balloon catheter (DBC) or a hydrogel-coated balloon catheter (HBC) inserted into the rabbit iliac artery, efficient gene transfer was easy in cases of modified recombinant replicationdefective adenovirus. Furthermore, using HBC they showed that cutaneous gene transfer was simple and that it was a clinically applicable technique, and if the endothelial layer was abraded, consistent transfection of medial smooth muscle 
cells was possible, and that percutaneous delivery of adenoviral vector with sitespecific arterial gene transfer was possible, showing the greater clinical possibilities of $\mathrm{HBC}$ compared to $\mathrm{DBC}$. Riessen et $\mathrm{al}^{46)}$ reported a marked increase in capillary densities in rabbits in which the femoral artery had been removed and in which $40 \mu \mathrm{g}$ of phVEGF $_{165}$ had been administered percutaneously into the iliac artery.

The first clinical trial of arterial gene therapy for the purpose of therapeutic angiogenesis was carried out by Isner et $\mathrm{al}^{47)}$ for ischemic vascular diseases in cases of ASO. In their method they cultured Escherichia coli encoding the VEGF $_{165}$ gene. Then they extracted the plasmid DNA and stored it in a dedicated storage freezer. Fifteen minutes before treatment hydrogel polymer coating of the inflated angioplasty balloon was applied by plasmid via pipette. This angioplasty balloon catheter was inserted into the contralateral common femoral artery advanced proximally to the intended site, and then after low-pressure inflation of the balloon for 5 minutes the balloon was deflated and the catheter withdrawn.

This method has many possible applications to ischemic cardiovascular diseases. In particular, this could be indicated in many cases of PTCA and PTA, which involve a high frequency of restenosis. In addition to the treatment of intrinsic lesions this method could be useful for promotion of reendothelialization in cases in which physical simulation or disruption caused by PTCA and also restenosis following PTCA and PTA could be inhibited by this method. ${ }^{36)}$ While there is as yet no actual proof of good long-term prognostic indications of the gene therapy method reported by Isner et al, there is much room for optimism.

However, there are many problems concerning gene therapy at present. For example, when using retrovirus vectors, infection due to homologous recombination within the body or carcinogenesis due to other mechanisms which are yet unknown, and other immunological factors is possible. As has been suggested by Isner et $\mathrm{al}^{47)}$ the criteria for patient selection should be extremely strict and it goes without saying that genc therapy should not be resorted to without careful consideration, but it is a novel approach which holds great promisc in terms of future therapeutic strategies.

\section{REFERENCES}

1. Dormandy JA, Thomas PRS. What is the natural history of a critically ischemic patient with and without his leg? In: Greenhalgh RM, Jamieson CW, Nicolaides AN, eds. Limb Salvage and Amputation for Vascular Disease. Philadelphia, PO: WB Saunders, 1988; 11-26.

2. European Working Group on Critical Leg Ischemia. Second European consensus document on chronic critical leg ischemia. Circulation 1991; 84 (Suppl IV): IV-1-26.

3. Gospodarowicz D. Localisation of a fibroblast growth factor and its effect alone and with hydrocortisone on 3 T3 cell growth. Nature 1974; 249: 123-7. 
4. Renko M, Quarto N, Morimoto T, Rifken DB. Nuclear and cytoplasmic localization of different basic fibroblast growth factor species. J Cell Physiol 1990; 144: 108-14.

5. Shing Y, Folkman J, Sullivan R, Butterfield C, Murray J, Klagsburn M. Heparin affinity: Purification of a tumor-derived capillary endothelial cell growth factor. Science 1984; $223: 1296-8$.

6. Yayon A, Klagsburn M. Autocrine regulation of cell growth and transformation by basic fibroblast growth factor. Cancer Metastasis Rev 1990; 9: 191-202.

7. Folkman J, Klagsburn M. Angiogenic factors. Science 1987; 235: 442-7.

8. Pasyk S, Schaper W, Shaper J, Pasyk K, Miskiewicz G, Steinseifer B. DNA synthesis in coronary collaterals after coronary artery occlusion in conscious dog. Am J Physiol 1982; 242: H1031-7.

9. Maciag T, Cerundolo J, Insley S, Kelly PR, Forand R. An endothelial cell growth factor from bovine hypothalamus: Identification and partial characterization. Proc Natl Acad USA 1979; 76: 5674 8.

10. Folkman J, Haudenschild C. Angiogenesis in vitro. Nature 1980; 288: 551-6.

11. Gay CG, Winkels BJA. Heparin-binding growth factor-1 stimulation of human endothelial cell induces platelet-derived growth factor A-chain gene. J Biol Chem 1990; 265: 3284-92.

12. Jaye M, Howk R, Burgess W, et al. Human endothelial cell growth factor: Cloning, nucleotide sequence, and chromosome localization. Science 1986; 233: 541-5.

13. Abraham JA, Mergia A, Whang JA, et al. Nucleotide sequence of bovine clone encoding the angiogenic protein, basic fibroblast growth factor. Science 1986; 223: 545-8.

14. D'Amore PA. Antiangiogenesis as a strategy for antimetastasis. Semin Thromb Hemost 1988; 14: 738.

15. Thornton SG, Mueller SN, Levine EM. Human endothelial cells: Use of heparin in cloning and longterm serial cultivation. Science 1983; 222: 623-5.

16. Gospodarowciz D, Cheng J. Heparin protects basic and acidic FGF from inactivation. J Cell Physiol 1986; 128: 475-84.

17. Yayon A, Klagsburn M, Esko JD, Leder P, Ornitz DM. Cell surface, heparin-like molecules are required for binding of basic fibroblast growth factor to its high affinity receptor. Cell 1991; 64: 841-8.

18. Gross JL, Moscatelli D, Jaffe EA, Rifken DB. Plasminogen activator and collagenase production by cultured capillary endothelial cells. J Cell Biol 1982; 95: 974-81.

19. Saksela $O$, Moscatelli D, Rifken DB. The opposing effects of basic fibroblast growth factor beta on the regulation of plasminogen activator activity in capillary endothelial cells. J Cell Biol 1987; 105: 957-63.

20. Herron GS, Werb Z, Dwyer K, Banda MJ. Secretion of metalloproteinases by stimulated capillary endothelial cells. J Biol Chem 1986; 261:2810 3.

21. Yanagisawa-Miwa A, Uchida $Y$, Nakamura $F$, et al. Salvage of infarcted myocardium by angiogenic action of basic fibroblast growth factor. Science 1992; 257: 1401-3.

22. Unger EF, Banai S, Shou M, et al. Basic fibroblast growth factor enhances myocardial collateral flow in a canine model. Am J Physiol 1994; 226: (Heart Circ Physiol 35): H1588-95.

23. Landau $\mathrm{C}$, Jacobs $\mathrm{AK}, \mathrm{Haudenschild} \mathrm{CC}$. Intrapericardial basic fibroblast growth factor induces myocardial angiogenesis in a rabbit model of chronic ischemia. Am Heart J 1995; 129: 924-31.

24. Chleboum JO, Martins RN, Michell CA, Chirila TV. bFGF enhances the development of the collateral circulation after acute arterial occlusion. Biochem Biophys Res Comm 1992; 185: 510-6.

25. Bauffour R, Berman J, Garb JL, Rhee SW, Kaufman J, Friedmann P. Enhanced angiogenesis and growth of collaterals by in vivo administration of recombinant basic fibroblast growth factor in a rabbit model of acute lower limb ischemia: Dose-response effect of basic fibroblast growth factor. J Vasc Surg 1992; 16: 181-91.

26. Norrby K. Basic fibroblast growth factor and de novo mammalian angiogenesis. Microvasc Res 1994; 48: $96-113$.

27. Chiba M, Sakai S, Nakata M, Toshima H. The role of basic fibroblast growth factor in myocardial hypertrophy. Circulation 1990; 32 (Suppl III); III-761.

28. Ferrara N, Henzel WJ. Pituitary follicular cells secrete a novel heparin-binding growth factor specific for vascular endothelial cells. Biochem Biophys Res Comm 1989; 161: 851-8.

29. Leung DW, Cachianes G, Kuang W-J, Goeddel DV, Ferrara N. Vascular endothelial growth factor is a secreted angiogenic mitogen. Science $1989 ; 246: 1306-9$.

30. Conn G, Soderman DD, Schaeffer M-T, Wile M, Hatcher VB, Thomas KA. Purification of a glyco- 
protein vascular endothelial cell mitogen from a rat glioma-derived cell line. Proc Natl Acad Sci USA 1990; 87: 1323-7.

31. Ferrara N, Houck KA, Jakeman LB, Winer J, Leung DW. The vascular endothelial growth factor family of polypeptides. J Cell Biochem 1991; 47; 211-8.

32. Houck KA, Leung DW, Rowland AM, Winer J, Ferrara N. Dual regulation of vascular endothelial growth factor bioavailability by genetic and proteolytic mechanisms. J Biol Chem 1992; 267: 26031-7.

33. Schweiki D, Itin A, Soffer D, Keschet E. Vascular endothelial growth factor induced by hypoxia may mediate hypoxia-inhibited angiogenesis. Nature 1992; 359: 843-5.

34. Brogi E, Wu T, Namiki A, Isner JM. Indirect angiogenic cytokines upregulate VEGF and bFGF gene expression in vascular smooth muscle cells, whereas hypoxia upregulates VEGF expression only. Circulation 1994; 90: 649-52.

35. Takeshita S, Zheng LP, Brogi E, et al. Therapeutic angiogenesis. A single intraarterial bolus of vascular endothelial growth factor augments revascularization in a rabbit ischemic hind limb model. J Clin Invest 1994; 93: 662-70.

36. Asahara T, Bauters C, Pastore C, et al. Local delivery of vascular endothelial growth factor accelerates reendothelialization and attenuates intimal hyperplasia in balloon-injured rat carotid artery. Circulation 1995; 91: 2793-801.

37. Bauters C, Asahara T, Zheng LP, et al. Recovery of disturbed endothelium-dependent flow in the collateral-perfused rabbit ischemic hind limb after administration of vascular endothelial growth factor. Circulation 1995; 91: 2802 9.

38. Banai S, Jaklitsch MT, Shou M, et al. Angiogenic-induced enhancement of collateral blood flow to ischemic myocardium by vascular endothelial growth factor in dogs. Circulation 1994; 89: 2183-9.

39. Nabel EG, Yang Z, Plautz G, et al. Recombinant fibroblast growth factor-1 promotes intimal hyperplasia and angiogenesis. Nature 1993; 362: 844-6.

40. Mesri EA, Federoff HJ, Brownlee M. Expression of vascular endothelial growth factor from a defective herpes simplex virus type 1 amplicon vector induces angiogenesis in mice. Girc Res 1995; 76: 161-7.

41. Ohno T, Gordon D, San H, et al. Gene therapy for vascular smooth muscle cell proliferation after arterial injury. Science 1994; 265: 781-4.

42. Gutzman RJ, Lemarchand P, Crystal RG, Epstein SE, Finkel T. Efficient and selective adenovirusmediated gene transfer into vascular neointima. Circulation 1993; 88: 2838-48.

43. Flugelman MY, Jaklitsch MT, Newman KD, Casscells W, Bratthauer GL, Dichek DA. Low level in ivivo gene transfer into the arterial wall through a perforated balloon catheter. Circulation 1992; 85: 1110-7.

44. Rome JJ, Shayani V, Flugelman MY, et al. Anatomic barriers influence the distribution of in vivo gene transfer into the arterial wall. Modeling with microscopic tracer particles and verification with a recombinant adenovirus vector. Arterioscler Thromb 1994; 14: 148-61.

45. Steg PG, Feldman LJ, Scoazec J-Y, et al. Arterial gene transfer to rabbit endothelial and smooth muscle cells using percutaneous delivery of an adenoviral vector. Circulation 1994; 90: 1648-56.

46. Riessen R, Isner JM. Prospects for site-specific delivery of pharmacologic and molecular therapies. J Am Coll Cardiol 1994; 23: 1234-44.

47. Isner JM, Walsh K, Symes J, et al. Arterial gene therapy for therapeutic angiogenesis in patients with peripheral artery discase. Circulation 1995; 91: 2687-92. 